\title{
Factor Activity Assays for Monitoring Extended Half-Life FVIII and Factor IX Replacement Therapies
}

\author{
Steve Kitchen, $\mathrm{PhD}^{1}$ Stefan Tiefenbacher, $\mathrm{PhD}^{2}$ Robert Gosselin, $\mathrm{CLS}^{3}$ \\ ${ }^{1}$ Sheffield Haemophilia and Thrombosis Centre, Sheffield, United \\ Kingdom \\ ${ }^{2}$ Colorado Coagulation, Laboratory Corporation of America ${ }^{\circledR}$ \\ Holdings, Englewood, Colorado

\begin{abstract}
Address for correspondence Steve Kitchen, PhD, Department of Coagulation, Royal Hallamshire Hospital, Glossop Road, Sheffield S10 2JF, United Kingdom (e-mail: Steve.Kitchen@sth.nhs.uk).
\end{abstract}

3 Department of Pathology and Laboratory Medicine, University of California Davis Health System, Sacramento, California

Semin Thromb Hemost 2017;43:331-337.

\begin{abstract}
The advent of modified factor VIII (FVIII) and factor IX (FIX) molecules with extended half-lives (EHLS) compared with native FVIII and FIX represents a major advance in the field of hemophilia care, with the potential to reduce the frequency of prophylactic injections and/or to increase the trough level prior to subsequent injections. Monitoring treatment through laboratory assays will be an important part of ensuring patient safety, including any tailoring of prophylaxis. Several approaches have been used to extend half-lives, including PEGylation, and fusion to albumin or immunoglobulin. Some of these modifications affect factor assays as routinely performed in hemophilia centers; so, laboratories will need to use FVIII and FIX assays which have been shown to be suitable on a product-by-product basis. For some products, there are marked differences between results obtained using one-stage or chromogenic assays and

Keywords

- Factor VIII assay

- FIX assay

- extended half-life FVIII

- extended half-life FIX results obtained using different reagents in the one-stage assay. The laboratory should use an assay in which the recovery of the product closely aligns with the assay used by the pharmaceutical company to assign potency to the product, so that the units reported by the laboratory agree with those used to demonstrate efficacy of the product during clinical trials. Reported assay differences in relation to several of the EHL FVIII and FIX molecules will be reviewed in this article.
\end{abstract}

Hemophilia describes the pathologic conditions where there is a hereditary deficiency of factor (F) VIII or FIX and includes both hemophilia A (FVIII) and hemophilia B (FIX). The diagnosis is typically made using laboratory methods to assess factor activity levels, and confirmed, in some countries, with additional genetic testing. Detailed guidance on the management of these conditions, including diagnosis, has been published by the World Federation of Hemophilia (WFH) in print ${ }^{1}$ and online. ${ }^{2}$ Once properly diagnosed, severe hemophilia patients require frequent and constant replacement therapy to avoid clinical and subclinical bleeding. Replacement therapy has substantially evolved over the years. When replacement therapy was first implemented, it was primarily based on treatment with human sources of plasma, either as fresh frozen plasma or cryopreci-

published online March 6, 2017
Issue Theme Laboratory Assessment of Hemostatic and Anticoagulant Therapy; Guest Editors: Robert C. Gosselin, CLS, and Dorothy M. Adcock, MD. pitate; this was followed in time by the use of isolated clotting factor concentrates. The unfortunate morbidities associated with this early mode of plasma-based factor replacement were the development of antibodies to transfused factor and inadvertent transmission of viral infections, including hepatitis and, tragically, acquired immunodeficiency syndrome (AIDS). In an effort to reduce both immune responses and reduce the risk of human plasma exposure, pharmaceutical companies developed more specific replacement therapies. Recombinant factor material became the standard of practice for hemophilia A factor replacement in some countries in the 1990s, and shortly thereafter for hemophilia B patients, and today it is the treatment of choice in many developed countries. ${ }^{3}$ The frequency of dosing is related to the half-life (clearance) of the
Copyright (C) 2017 by Thieme Medical Publishers, Inc., 333 Seventh Avenue, New York, NY 10001, USA. Tel: +1(212) 584-4662.
DOI http://dx.doi.org/ 10.1055/s-0037-1598058. ISSN 0094-6176. 
infused product. Doses required depend on the concentration required to maintain sufficient factor levels to prevent bleeding and are patient dependent. B-domain deleted (BDD) recombinant FVIII was the first modified FVIII product introduced. More recently, efforts have focused on modifications to the factor protein to extend the half-life and thus decrease the frequency of therapy without increasing the risk of bleeding. ${ }^{4}$ The new long-acting therapeutic replacement products include modifications to the factor by fusion of Fc region of $\operatorname{IgG}_{1}$ immunoglobulin (-Fc) or albumin, or nonspecific or site-specific attachment of polyethylene glycol (PEG) of different molecular weights ${ }^{5}$ (-Table 1).

In addition to the initial diagnostic role, the laboratory plays a continuous and important ancillary role for hemophilia patients. To ensure optimal therapy, the laboratory must be able to accurately measure the native plasma and replacement FVIII and FIX activity at trough, peak, or during therapy to confirm that factor levels, achieved during a particular dosing regimen for a specific product, are adequate for each patient.

Factor activity testing can be performed using several different techniques, including the one-stage clotting assay based on activated partial thromboplastin time (APTT), twostage clotting assay based on thromboplastin generation test, and chromogenic methods. ${ }^{6}$ It is clear from several proficiency testing programs such as WFH IEQAS, UK NEQAS, ECAT, RCPAQAP, and CAP ${ }^{7,8}$ and from field surveys of practice $^{9}$ that the vast majority of clinical laboratories currently use one-stage clotting factor assays for clinical diagnosis of hemophilia and for monitoring factor replacement therapies. For one-stage APTT-based clotting assays, there are a wide variety of APTT reagents used for FVIII and FIX activity testing, which differ in phospholipid source (synthetic or extract from plant or animal), type, and concentration, as well as activator type (e.g., ellagic acid, celite, kaolin, silica of various types, polyphenols). Factor-depleted plasma used may either be sourced from congenital-deficient hemophilia A or B patients or is more commonly prepared by targeted removal of FVIII or FIX from normal pooled plasma using immunodepletion. Removal of von Willebrand factor (VWF) from FVIII-depleted plasma may be an unwanted side effect

Table 1 Characteristics of some extended half-life FVIII and FIX replacement products

\begin{tabular}{|l|l|l|l|}
\hline Product & Manufacturer & Property & Mean half-life $($ h) \\
\hline N8 GP & Novo Nordisk & 40 KD peg & $19($ age $>17)$ \\
\hline Bay 94-9027 & Bayer & 60 KD peg & 18.2 (age $>17)$ \\
\hline BAX 855 & Baxalta/Shire & 20 KD peg & 14.3 (age 12-65) \\
\hline rFVIIIFc & Biogen/Sobi & Fc fusion & 18.8 (age $>11)$ \\
\hline rFIXFc & Biogen/Sobi & Fc fusion & $\begin{array}{l}\text { Study 1: } 58(\text { age }>18) \\
\text { Study 2: } 82(\text { age }>11)\end{array}$ \\
\hline N9 GP & Novo Nordisk & 40 KD peg & $\begin{array}{l}\text { Study 1: } 96(\text { age 12-65) } \\
\text { Study 2: 93 (age 12-65) }\end{array}$ \\
\hline rFIX-FP & CSL Behring & $\begin{array}{l}\text { Albumin } \\
\text { fusion }\end{array}$ & $\begin{array}{l}\text { Study 1: 92 (age 12-65) } \\
\text { Study 2: 95 (age 12-65) }\end{array}$ \\
\hline
\end{tabular}

${ }^{a}$ Reviewed in Collins et al. ${ }^{37}$ of the immunodepletion process. The source of FVIIIdeficient plasma used in the FVIII one-stage assay has been shown to influence the FVIII activity results. ${ }^{10}$ Additionally, the analyzers used for factor activity testing (i.e., mechanical or optical clot detection) and/or the particular assay protocols and setups used for factor activity testing (single, dual, or hybrid calibration curves with or without extrapolation), as well as the material used for calibration, may influence or limit accurate measurement of factor activity, especially at trough or factor levels below $0.10 \mathrm{IU} / \mathrm{mL} .^{11}$

Discrepancies in reported FVIII activity when assayed by one-stage or chromogenic methods in mild hemophilia $A$ patients have been described. ${ }^{12-14}$ Typically, the result obtained from one-stage assays are higher than the chromogenic methods, although the reverse may also occur. Some cases in which the chromogenic result is greater do not have a clinical picture consistent with mild hemophilia and some of these subjects are thought to have a polymorphism rather than a clinically relevant defect. ${ }^{15}$ When measuring postinfusion levels, differences between the one-stage clot and chromogenic FVIII activity from patients receiving certain full-length recombinant FVIII products ${ }^{16}$ or ReFacto, a BDD recombinant FVIII replacement product, have been reported. ${ }^{17-20}$ Other full-length recombinant products can be accurately measured with either chromogenic or onestage assays. ${ }^{21,22}$ The discrepancy between the one-stage clot and chromogenic FVIII activity assay in postinfusion samples can be mitigated using a specific reference standard, which has been adopted as an approach in the United Kingdom $^{21}$ but has not been widely accepted elsewhere. The newer recombinant FVIII (rFVIII) products, which contain modifications to either the b-domain and/or modifications to the actual therapeutic protein (e.g., single chain protein sequence modification, Fc-coupling, PEGylation), have raised awareness about the appropriate method for monitoring patients receiving these agents. ${ }^{5,23}$ The purpose of this article is to review the available assay data for measuring the new generation of extended half-life (EHL) products for FVIII and FIX.

\section{Hemophilia A rFVIII and Modified Replacement Therapy}

Published information on the behavior of the new generation rFVIII replacement products is limited to selected field studies for some of the products, ${ }^{24-26}$ as well as data presented by the respective product manufacturers at a workshop organized by the European Directorate for the Quality of Medicines and HealthCare and the European Medicines Agency (EMA). ${ }^{5,27}$ A summary of which APTT reagents recover one-stage FVIII activity close to labeled potency is shown in - Table $\mathbf{2}$ for different FVIII concentrates.

A comparative field study on the BDD-deleted rFVIII-Fc fusion protein from Biogen/SOBI (approved in the United States in 2014 under the trade name ELOCTATE and approved in Europe under the trade name ELOCTA) demonstrated on average a $20 \%$ higher activity using chromogenic FVIII assays when compared with labeled potency, even though the 
Table 2 Assays based on the current available literature are suggested to appropriately recover selected EHL FVIII products

\begin{tabular}{|c|c|c|c|}
\hline & N8 GP & Bay 94-9027 & rFVIIIFC \\
\hline $\begin{array}{l}\text { Relevant } \\
\text { references }\end{array}$ & $\begin{array}{l}29,30 \\
31,34\end{array}$ & 35 & $25,28,29$ \\
\hline $\begin{array}{l}\text { Chromogenic } \\
\text { FVIII assay }\end{array}$ & Yes $^{\mathrm{a}}$ & Yes $^{a}$ & Yes $^{\mathrm{a}}$ \\
\hline \multicolumn{4}{|c|}{ One-stage reagents } \\
\hline STA-PTT A & No & No & Yes $^{\mathrm{b}}$ \\
\hline STA-C.K. Prest & Yes & $?$ & Yes $^{\mathrm{b}}$ \\
\hline Actin FS & Yes & $?$ & Yes $^{\mathrm{b}}$ \\
\hline Actin FSL & Yes & $?$ & Yes $^{a}$ \\
\hline Pathromtin SL & $?$ & $?$ & Yes $^{\mathrm{a}}$ \\
\hline SynthASil & $?$ & $?$ & $Y_{e s}^{a}$ \\
\hline SynthAFax & No & Yes & $?$ \\
\hline DG Synth & Yes & $?$ & $?$ \\
\hline Cephascreen & Yes & Yes & Yes $^{\mathrm{a}}$ \\
\hline APTT Sp & No & No & $?$ \\
\hline
\end{tabular}

Notes: For one-stage assay results, published data from articles or abstracts in which particular reagents have been fully identified are included. "Yes" means results were within $25-30 \%$ of the expected result based on labeled potency. "No" means results were more than $30 \%$ different from expected. "?" means authors are unaware of any data at the time of writing this article.

${ }^{a}$ Reagents included in the study of Sommer et al. ${ }^{24}$

${ }^{\mathrm{b}}$ Not all kits have been studied.

potency was assessed using an unspecified chromogenic method. ${ }^{24}$ The recoveries for ADVATE, a recombinant factor VIII product, were comparable for one-stage and chromogenic assays, falling within $\pm 20 \%$ of target for the levels tested $(0.05-0.80 \mathrm{IU} / \mathrm{mL})$, with potency assigned by an unspecified single-stage assay. Comparing chromogenic versus single-stage clotting assays, there was around 25\% higher recovery with chromogenic assay assessment of samples containing $>0.22 \mathrm{IU} / \mathrm{mL}$ rFVIII-Fc. ${ }^{24}$ This increased recovery of rFVIII-Fc in the chromogenic assay has also been observed in postinfusion samples of patients treated with rFVIII-Fc. ${ }^{28}$ There were no important APTT reagent-dependent differences in recoveries and the authors of the field study concluded that both routine one-stage and chromogenic assays could be used for monitoring without special assay conditions. ${ }^{24}$ For ADVATE (full-length BDD rFVIII) and the bdomain truncated rFVIII (N8 or Novo Eight), equivalent factor recovery was reported for the one-stage clot assay using 15 different APTT reagents testing drug-enriched factor VIII-deficient plasma with product concentrations ranging between 0.03 and $0.9 \mathrm{IU} / \mathrm{mL} .^{25}$ Although there were biases noted for both one-stage clotting assays and chromogenic assays for measuring ADVATE or N8, the authors concluded that these differences "were judged to be without clinical relevance." $25^{25}$

Data from a collaborative FVIII field study ${ }^{26}$ reported comparable intra- and inter-assay variability for PEGylated, full-length rFVIII (i.e., BAX 855, approved in the United States in 2015 under the trade name ADYNOVATE) when compared with full-length rFVIII (ADVATE) using both one-stage clot and chromogenic assays. For ADYNOVATE, no significant APTT reagent-dependent recoveries in the one-stage assay was observed, although ellagic acid/phenol type APTT reagents did show a tendency for higher recovery compared with silica and kaolin-type reagents. The ratio of one-stage to chromogenic assay results was similar for ADVATE and ADYNOVATE with ratios of 0.88 and 0.82 (i.e., higher by chromogenic assay) for samples containing $0.8 \mathrm{IU} / \mathrm{mL}$ and ratios of 1.44 and 1.25 (i.e., higher by one-stage) for samples with $0.05 \mathrm{IU} / \mathrm{mL}$. It was concluded that plasma levels of ADYNOVATE can be adequately assessed using routine onestage or chromogenic FVIII activity assays. ${ }^{26}$

Not all one-stage FVIII APTT reagents are suitable to measure glycoPEGylated N8 (N8-GP, Novo Nordisk). N8-GP was accurately measured (i.e., within $\pm 25 \%$ from expected) by one-stage assays using Actin FS (Siemens Healthcare Diagnostics, Marburg GmbH) or DG-APTT Synth (Grifols, Barcelona, Spain), but significantly underestimating N8-GP using SynthAFax (Instrumentation Laboratory, Bedford) one-stage assay. ${ }^{29}$ Likewise, acceptable recovery for N8-GP was demonstrated for Actin FSL (Siemens Healthcare Diagnostics, Marburg GmbH) and STA-CK Prest (Diagnostica Stago, Asnières sur Seine Cedex, France), with STA-PTT A(Diagnostica Stago) one-stage assay significantly under-recovering N8-GP. ${ }^{30}$ Conflicting data regarding accurate recovery arose between studies with N8-GP and Pathromtin SL (Siemens Healthcare Diagnostics, Marburg GmbH) and SynthASil (Instrumentation Laboratory, Bedford, MA), as well as some chromogenic methods. ${ }^{29-33}$ Recently, the recovery of N8-GP was evaluated using four different chromogenic FVIII assays, calibrated using normal pooled plasma. ${ }^{34}$ Suitable recovery $( \pm 30 \%)$ for simulated postinfusion samples of N8-GP was demonstrated for three of the four chromogenic assays, that is, Coatest SP (Chromogenix, Instrumentation Laboratory, Bedford), Coamatic (Chromogenix, Instrumentation Laboratory), and the FVIII chromogenic assay (Siemens Healthcare Diagnostics, Marburg GmbH). In the Biophen FVIII:C (Hyphen BioMed, Neuville-sur-Oise, France), N8-GP demonstrated some nonlinearity, resulting in significant over-recovery of N8-GP at concentrations of $0.2 \mathrm{IU} / \mathrm{mL}$. An international field study for N8-GP has recently been initiated through ECAT and data should be available in the near future.

An in-house study using BAY 94-9027 (Bayer, PEGylated BDD rFVIII) spiked plasma samples ranging between 0.05 and $1.0 \mathrm{IU} / \mathrm{mL}$ demonstrated acceptable recovery in the chromogenic assay, and with APTT reagents containing ellagic acid, but not with APTT reagents containing silica (underestimation of factor activity). ${ }^{35}$ Not all available reagents incorporating silica as activator were studied. The mechanism for the differences between APTT activators and factor recovery is presently unclear, but it was suggested that the PEG moiety of BAY 94-9027 may disturb activation of FXII on the silica surface. ${ }^{35}$ Interestingly, silica in some APTT reagents directly activates a PEGylated FIX molecule leading to overestimation of FIX activity in one-stage assays utilizing such reagents ${ }^{36}$ as discussed further below. 
Limited data are available on the b-domain truncated single-chain rFVIII (i.e., rVIII-SingleChain) from CSL Behring, approved in 2016 under the trade name AFSTYLA. Heavy and light chains of FVIII are covalently linked in the modification of this rFVIII, which results in an increased affinity of the product to bind VWF. There is some extension of the half-life as compared with ADVATE, although so far there is no full consensus that the degree of half-life prolongation is sufficient to classify this product as an EHL. Preliminary results of an international multicenter field study presented at the ISTH annual meeting in 2015 suggested that unlike chromogenic methods, one-stage assays consistently underestimate AFSTYLA; however, as the underestimation bias in the onestage assay was consistent and reproducible, the authors suggested that both one-stage and chromogenic FVIII assays can be used to measure post-administration levels of AFSTYLA therapy in plasma, as long as a correction factor for the one-stage is used. ${ }^{37}$ Reference to such a correction factor included in the prescribing information for AFSTYLA in the Warnings and Precautions section includes the following statement:

Monitor plasma Factor FVIII activity in patients receiving AFSTYLA using either the chromogenic assay or the onestage clotting assay, which is routinely used in US clinical laboratories. The chromogenic assay result most accurately reflects the clinical hemostatic potential of AFSTYLA and is preferred. The one-stage clotting assay result underestimates the factor VIII activity level compared to the chromogenic assay result by approximately one-half. If the onestage clotting assay is used multiply the result by a conversion factor of 2 to determine the patient's FVIII activity level. Incorrect interpretation of the FVIII activity obtained by the one-stage assay could lead to unnecessary additional dosing, higher chronic dosing, or investigations for an inhibitor.

The inclusion of such statements in the prescribing information underlines the potential impact of assay differences on patient management with an adverse effect if these assay effects are not taken into account.

We are unaware of any data confirming that such correction factors remain constant over subsequent lot numbers of reagents used in FVIII assays, which would be needed to show that the bias between one-stage and chromogenic assays is consistent. Since it is known that different lot numbers of APTT reagents may not be identical, ${ }^{38}$ it remains to be demonstrated that this approach is safe enough for routine use in relation to FVIII assays. One expert group has recently recommended against the use of correction factors in determining accurate plasma concentration ${ }^{39}$; so, with this product the authors prefer using a chromogenic assay over one-stage assay followed by adjustment/correction for monitoring this product.

\section{Hemophilia B rFIX and Modified Replacement Therapy}

There is some evidence that differences in the APTT one-stage assay may influence the diagnosis of mild hemophilia $B{ }^{40}$
Higher FIX activity in mild type 2 (discordant FIX activity to FIX antigen measurements) patients with hemophilia B occurred for one-stage assays performed using Actin FS (Siemens Healthcare Diagnostics, Marburg GmbH) compared with FIX activity determined using STA-PTT A or STA-CK PREST (both Diagnostica Stago). As not all clinical or field studies incorporated every commercially available one-stage APTT reagents used for FIX activity testing, one should not imply that reagents using the same activator (e.g., ellagic acid, kaolin, silica) would perform similarly to those published ( - Table 3 ).

Ideally, similar to FVIII products, post treatment monitoring should be performed using factor assays that recover FIX activity of a particular product similar to the method used for potency determination. Currently, licensed plasma derived, full-length recombinant FIX concentrates (i.e., BeneFIX, RIXUBIS), glycoPEGylated products (i.e., N9-GP), and those products fused with albumin (i.e., IDELVION) or Fc domain of IgG1 (i.e., ALPROLIX) all have potencies labeled using the onestage assay. ${ }^{5}$ There have, however, been reported discrepancies between chromogenic and one-stage FIX assays in samples containing standard rFIX. ${ }^{41}$ In a study of patients receiving two different rFIX therapies, the chromogenic FIX results were approximately 70\% of the value of one-stage APTT FIX activity results when the two rFIX concentrates were assayed. ${ }^{42}$

Table 3 Assays that can be safely used to monitor selected EHL FIX products

\begin{tabular}{|c|c|c|c|}
\hline Reagent name & N9 GP & rFIXFc & FIX-Albumin \\
\hline $\begin{array}{l}\text { Relevant } \\
\text { references }\end{array}$ & $\begin{array}{l}36,43, \\
44,45,46\end{array}$ & 46,47 & 49 \\
\hline $\begin{array}{l}\text { Chromogenic } \\
\text { FIX assay }\end{array}$ & Yes & Yes & $?$ \\
\hline \multicolumn{4}{|c|}{ One-stage reagents } \\
\hline STA-PTT A & No & Yes & Yes \\
\hline STA-C.K. Prest & No & No & No \\
\hline Actin & No & $?$ & $?$ \\
\hline Actin FS & No & Yes & No \\
\hline Actin FSL & No & Yes & $?$ \\
\hline Pathromtin SL & No & Yes & Yes \\
\hline SynthASil & No & Yes & Yes \\
\hline SynthAFax & Yes & $?$ & $?$ \\
\hline DG Synth & Yes & $?$ & $?$ \\
\hline Cephascreen & Yes & Yes & $?$ \\
\hline APTT-SP & No & $?$ & $?$ \\
\hline Auto APTT & $?$ & Yes & $?$ \\
\hline Platelin L & $?$ & Yes & $?$ \\
\hline DAPTIN & Yes & $?$ & $?$ \\
\hline
\end{tabular}

Notes: For one-stage assay results, published data from articles or abstracts in which particular reagents have been fully identified are included. "Yes" means results were within $25-30 \%$ of the expected result based on labeled potency. "No" means results were more than $30 \%$ different from expected. "?" means authors are unaware of any data at the time of writing this article. 
Furthermore, the prescribing information for RIXUBIS indicates that one-stage APTT FIX assay results can be affected by the type of APTT reagent used, with up to $40 \%$ differences between reagents noted.

In a recent publication assessing glycoPEGylated rFIX(N9-GP, Novo Nordisk), acceptable recovery in the one-stage assay was demonstrated for enriched samples using SynthAFax (Werfen, Barcelona, Spain) or DG Synth (Grifols, Barcelona, Spain), with significant under-recovery in assays using Actin, Actin FS, Actin FSL (Siemens Healthcare Diagnostics, Marburg $\mathrm{GmbH}$ ) and SynthASil (Instrumentation Laboratory), and significant overrecovery in assays using Pathromtin SL (Siemens Healthcare Diagnostics, Marburg GmbH) or APTT-SP (Werfen, Barcelona, Spain).$^{43}$ In some case, the measured activity was 20 to 30 times higher than labeled potency ${ }^{43}$ which would result in the potential for very marked under-dosing of patients as a consequence. One-stage assays using DAPTIN, ${ }^{44}$ SynthAFax, ${ }^{44}$ or Cephascreen, ${ }^{44,45}$ as well as both Rossix and Hyphen chromogenic assays ${ }^{45,46}$ were shown to have acceptable recoveries for this product. It has now been shown that the significant overestimation of N9GP using Pathromtin SL and APTT-SP APTT reagent is related to a silica-mediated premature activation of PEGylated FIX which leads to massive activated FIX (FIXa) generation during the contact activation phase of the one-stage FIX activity assay (prior to the recalcification step). ${ }^{34}$ This direct activation does not occur with at least one other silica-based APTT reagent (SynthASil), suggesting that the type of silica is relevant and other silica-based reagents should be studied individually. Based on these data, only chromogenic FIX methods or selected one-stage APTT assays (i.e., SynthAFax, DAPTIN, cephascreen, and DG Synth) would be acceptable for monitoring patients receiving N9GP.

A recent field study assessing FIX activity in patients receiving rFIX-Fc (Biogen, factor IX fused with Fc fragment, approved in the United States in 2014 under the trade name ALPROLIX) indicated that activity is dependent on the APTT reagent used for assay. ${ }^{44}$ One-stage assays using ellagic acid showed a tendency to overestimate factor activity, whereas silica-based reagents recovered rFIX-Fc within acceptable limits. ${ }^{47}$ The tendency to overestimate FIX-Fc activity when using ellagic acid-based APTT reagents should not have a significant clinical impact (e.g., dose adjustment), and ellagic acid-based reagents would be suitable for monitoring patients receiving ALPROLIX infusions. It should be noted that one-stage assays using kaolin activators (STA-CK PREST, Diagnostica Stago) underestimate the FIX activity of FIX-FC by approximately 30 to $50 \%{ }^{46}$ Use of this reagent in onestage FIX assays is not optimal for monitoring rFIXFc, and alternative methods should be employed at institutions that may treat patients with this product.

A study in patients receiving rFIX fused with albumin (CSL Behring, approved in the United States in 2016 under the trade name IDELVION), FIX activity measured with the one-stage assay using Pathromtin SL (Siemens Healthcare Diagnostics, Marburg $\mathrm{GmbH}$ ) reagent, demonstrated equivalent results compared with FIX antigen levels across a range of concentrations. ${ }^{48}$ A recent poster presentation including data on both spiked and clinical trial (postinfusion) samples ${ }^{49}$ showed that one-stage FIX assays performed with Actin FS or a kaolinactivated reagent (CK PREST, Diagnostica Stago) underestimated FIX potency by approximately $50 \%$. Assays with a range of other APTT reagents recovered close to the expected value and were therefore suitable for use in one-stage assays. No data on chromogenic FIX assays were included. More data are required using other one-stage and chromogenic FIX methods to further determine the optimal method(s) for measuring FIX concentration for this product.

There are several barriers which have restricted the introduction of chromogenic FVIII and FIX assays into routine laboratory use, including the perception of test complexity and increased costs compared with one-stage assays. In fact, chromogenic FIX and FVIII assays can be automated using the same analyzers as those currently used for one-stage assays, although available instrument applications for these assays are still limited and have not yet been optimized for most available instrument platforms. The implication is that institutions employing these methods will need to ensure the assay's performance using external quality assurance programs, and if available well-characterized plasma samples, prior to reporting patient results. More validated chromogenic assay applications are needed and some efforts are underway. ${ }^{45}$ Lack of approved applications has been an important obstacle in North America, where experts have recommended that laboratories routinely monitoring hemophilia patients strongly consider addition of chromogenic FVIII assays and FIX assays when these assays are approved by the Food and Drug Administration. ${ }^{50}$ With respect to costs it has been theorized that with optimized use of reagents, chromogenic FVIII assays may be less expensive than one-stage methods, and that the cost differential for FIX can be small. ${ }^{51}$ However, suboptimal reporting of factor activity in patients receiving these products may have increased institutional costs due to increased drug utilization (if underestimating factor activity) or patient morbidity (if overestimating factor activity) secondary to bleeding.

\section{Conclusion}

New factor replacement products with EHLs present opportunities for improvements in patient care but have created challenges for laboratories that traditionally use one-stage APTT factor assays to assess therapy. With the new products, assay methodology, and type of reagent, many cause clinically significant over- or underestimation of plasma concentration with the potential to adversely affect patient management. Understanding and taking into account the assay issues reviewed in this article is an important component of the safe and effective introduction of EHL concentrates into routine patient management around the world.

The commonly used laboratory methods for measuring FVIII or FIX activity may not be optimal for some modified rFVIII or rFIX products. The most consistent laboratory methods that can adequately measure modified rFVIII products are based on chromogenic principles. Further investigation into calibration practice is required, but a single plasma calibrator source may not be optimal for all products. Any laboratory that measures factor activity in hemophilia 
patients should have knowledge about (1) which replacement factor the patient is receiving and (2) whether their current method(s) for determining factor activity provides an accurate (within 25\% of target) measurement of that particular replacement therapy. For those laboratories that do not have the optimal measuring techniques, the treating clinician must be informed about the potential biases (overor underestimating factor activity) and an alternative means of measuring accurate concentration provided.

\section{References}

1 Srivastava A, Brewer AK, Mauser-Bunschoten EP, et al; Treatment Guidelines Working Group on Behalf of The World Federation Of Hemophilia. Guidelines for the management of hemophilia. Haemophilia 2013;19(1):e1-e47

2 World Federation of Haemophilia (WFH) Hemophilia Treatment Guidelines. Available at: http://www.wfh.org/en/resources/wfhtreatment-guidelines. Accessed September 30, 2016

3 Keeling D, Tait C, Makris M. Guidelines on the selection and use of therapeutic products to treat haemophilia and other hereditary bleeding disorders. A United Kingdom Haemophilia Center Doctors' Organisation (UKHCDO) guideline approved by the British Committee for Standards in Haematology. Haemophilia 2008; 14(4):671-684

4 Young G, Mahlangu JN. Extended half-life clotting factor concentrates: results from published clinical trials. Haemophilia 2016;22 (Suppl 5):25-30

5 Dodt J, Hubbard AR, Wicks SJ, et al. Potency determination of factor VIII and factor IX for new product labelling and postinfusion testing: challenges for caregivers and regulators. Haemophilia 2015;21(4):543-549

6 Kitchen S, McCraw A. 2010Diagnosis of Haemophilia and Other Bleeding Disorders. 2nd ed. World Federation of Haemophilia. Available at: http://www.wfh.org/en/page.aspx?pid=877 (Accessed September 30, 2016)

7 Jennings I, Kitchen DP, Woods TAL, Kitchen S, Walker ID, Preston FE. Laboratory performance in the World Federation of Hemophilia EQA programme, 2003-2008. Haemophilia 2009;15(2):571-577

8 Favaloro EJ, Meijer P, Jennings I, et al. Problems and solutions in laboratory testing for hemophilia. Semin Thromb Hemost 2013; 39(7):816-833 [ Erratum in: Semin Thromb Hemost. 2014 Feb;40 (1):135]

9 Kitchen S, Signer-Romero K, Key NS. Current laboratory practices in the diagnosis and management of haemophilia: a global assessment. Haemophilia 2015;21(4):550-557

10 Butenas S, Parhami-Seren B, Mann KG. The influence of von Willebrand factor on factor VIII activity measurements. J Thromb Haemost 2009;7(1):132-137

11 Verbruggen B, Meijer P, Novákova I, Van Heerde W. Diagnosis of factor VIII deficiency. Haemophilia 2008;14(Suppl 3):76-82

12 Parquet-Gernez A, Mazurier C, Goudemand M. Functional and immunological assays of FVIII in 133 haemophiliacs-characterization of a subgroup of patients with mild haemophilia $A$ and discrepancy in 1- and 2-stage assays. Thromb Haemost 1988; 59(2):202-206

13 Duncan EM, Duncan BM, Tunbridge LJ, Lloyd JV. Familial discrepancy between the one-stage and two-stage factor VIII methods in a subgroup of patients with haemophilia A. Br J Haematol 1994; 87(4):846-848

14 Bowyer AE, Van Veen JJ, Goodeve AC, Kitchen S, Makris M. Specific and global coagulation assays in the diagnosis of discrepant mild hemophilia A. Haematologica 2013;98(12):1980-1987

15 Bowyer AE, Goodeve A, Liesner R, Mumford AD, Kitchen S, Makris M. p.Tyr365Cys change in factor VIII: haemophilia A, but not as we know it. Br J Haematol 2011;154(5):618-625
16 Lusher JM, Hillman-Wiseman C, Hurst D. In vivo recovery with products of very high purity-assay discrepancies. Haemophilia 1998;4(4):641-645

17 Morfini M, Cinotti S, Bellatreccia A, Paladino E, Gringeri A Mannucci PM; ReFacto-AICE Study Group. A multicenter pharmacokinetic study of the B-domain deleted recombinant factor VIII concentrate using different assays and standards. J Thromb Haemost 2003;1(11):2283-2289

18 Ingerslev J, Jankowski MA, Weston SB, Charles LA; ReFacto Field Study Participants. Collaborative field study on the utility of a BDD factor VIII concentrate standard in the estimation of BDDr Factor VIII:C activity in hemophilic plasma using one-stage clotting assays. J Thromb Haemost 2004;2(4):623-628

19 Pouplard C, Ternisien C, Desconclois C, Lasne D, Aillaud MF, Caron C. Discrepancies between one stage assay and chromogenic substrate assay in patients treated with recombinant or plasma-derived FVIII and usefulness of a specific standard in ReFacto AF(®) -treated patients. Haemophilia 2016;22:e101

20 Recht M, Nemes L, Matysiak M, et al. Clinical evaluation of moroctocog alfa (AF-CC), a new generation of B-domain deleted recombinant factor VIII (BDDrFVIII) for treatment of haemophilia A: demonstration of safety, efficacy, and pharmacokinetic equivalence to full-length recombinant factor VIII. Haemophilia 2009; 15(4):869-880

21 Kitchen S, Jennings I, Makris M, Kitchen DP, Woods TAL, Walker ID. Factor VIII assay variability in postinfusion samples containing full length and B-domain deleted FVIII. Haemophilia 2016;22(5): 806-812

22 Kitchen S, Beckmann H, Katterle Y, Bruns S, Tseneklidou-Stoeter D, Maas Enriquez M. BAY 81-8973, a full-length recombinant factor VIII: results from an international comparative laboratory field study. Haemophilia 2016;22(3):e192-e199

23 Hubbard AR, Dodt J, Lee T, et al; Factor VIII and Factor IX Subcommittee of The Scientific and Standardisation Committee of The International Society on Thrombosis and Haemostasis. Recommendations on the potency labelling of factor VIII and factor IX concentrates. J Thromb Haemost 2013;11(5):988-989

24 Sommer JM, Moore N, McGuffie-Valentine B, et al. Comparative field study evaluating the activity of recombinant factor VIII Fc fusion protein in plasma samples at clinical haemostasis laboratories. Haemophilia 2014;20(2):294-300

25 Viuff D, Barrowcliffe T, Saugstrup T, Ezban M, Lillicrap D. International comparative field study of N8 evaluating factor VIII assay performance. Haemophilia 2011;17(4):695-702

26 Turecek PL, Romeder-Finger S, Apostol C, Bauer A, Burger D, Hunt A, Gritsch H. A world-wide survey and field study FVIII in clinical hemostasis laboratories to evaluate FVIII:C activity assay variability of ADYNOVATE and OBIZUR in comparison to ADVATE. Haemophilia 2016;22(6):957-965

27 EMAJoint EMA/EDQM workshop on characterization of new clotting-factor concentrates (factor VIII and factor IX) with respect to potency assays used for labeling and testing of postinfusion samples. Available at: www.ema.europa.eu/docs/en_GB/ document_library/Report/2014/07/WC500169760.pdf (Accessed 2014) 2014

28 Pouplard C, Caron C, Kitchen S, Wiken M, Falk Am Ferrante F, Lethagen $S$. High agreement rate between ellagic acid-based onestage and chromogenic assays for rFVIIIFc post infusion samples in the A-LONG study. (Abstract) J Thromb Haemost 2016;14 (Suppl 1):58

29 Hillarp A, Bowyer A, Ezban M, Persson P, Kitchen S. Measuring FVIII activity of glycopegylated recombinant FVIII, N8-GP with commercially available one stage clotting assay and chromogenic assay: a two centre study. Haemophilia 2017; doi: 10.1111/hae.13168

30 Tiefenbacher S, Robinson MM, Ross EL, et al. Comparison of FVIII activity of select novel recombinant FVIII replacement products in commonly used FDA approved one-stage clot assay systems. . (Abstract)J Thromb Haemost 2015;13(Suppl 2):566 
31 Lochu A, Romari N, Beltran J, Magdelaine A, Hermit MB, Ezban M. Influence of FVIII and FIX pegylation on FVIII and FIX activity based APTT assays. . (Abstract)J Thromb Haemost 2013;11(Suppl 2):970

32 Brand-Staufer BC, Koch K, Balabanov S, Clausen WHO, Exban M. Single center experience evaluating activity of N8-GP with onestage clotting assay. (Abstract)J Thromb Haemost 2015;13 (Suppl 2):829

33 Doyle MJ, Khan A, DiStasio K, Sullivan A, Triscott M. Accurate recovery of pegylated and non-pegylated therapeutic FVIII, using a specific aPTT reagent, and application on an automated coagulation analyzer. (Abstract)J Thromb Haemost 2015;13(Suppl 2):295

34 Pickering W, Hansen M, Kjalke M, Ezban M. Factor VIII chromogenic assays can be used for potency labeling and postadministration monitoring of N8-GP. J Thromb Haemost 2016;14(8):1579-1587

$35 \mathrm{Gu}$ JM, Ramsey P, Evans V, et al. Evaluation of the activated partial thromboplastin time assay for clinical monitoring of PEGylated recombinant factor VIII (BAY 94-9027) for haemophilia A. Haemophilia 2014;20(4):593-600

36 Rosén P, Rosén S, Ezban M, Persson E. Overestimation of $\mathrm{N}$ glycoPEGylated factor IX activity in a one-stage factor IX clotting assay owing to silica-mediated premature conversion to activated factor IX. J Thromb Haemost 2016;14(7):1420-1427

37 St. Ledger K, Feussner A, Kalina U, et al. The FVIII plasma activity of rVIII-SingleChain can be measured in both the one-stage and chromogenic substrate assays. (Abstract)J Thromb Haemost 2015; 13(Suppl 2):540

38 Shojania AM, Tetreault J, Turnbull G. the variations between heparin sensitivity of different lots of activated partial thromboplastin time reagents produced by the same manufacturer. Am J Clin Pathol 1988;89:19-23

39 Collins P, Chalmers E, Chowdary P, et al. The use of enhanced halflife coagulation factor concentrates in routine clinical practice: guidance from UKHCDO. Haemophilia 2016;22(4):487-498

40 Pouplard C, Trossaert M, LE Querrec A, Delahousse B, Giraudeau B, Gruel Y. Influence of source of phospholipids for APTT-based factor IX assays and potential consequences for the diagnosis of mild haemophilia B. Haemophilia 2009;15(1):365-368

41 Wilmot HV, Hogwood J, Gray E. Recombinant factor IX: discrepancies between one-stage clotting and chromogenic assays. Haemophilia 2014;20(6):891-897

42 Gritsch H, Romeder-Finger S. Scheiflinger, Turecek PL. Potency assignment and measurement of recombinant FIX activity in human plasma- impact of APTT reagents on the one-stage clotting assay. Haemophilia 2014;20(Suppl 2):56(abstract)

43 Bowyer AE, Hillarp A, Ezban M, Persson P, Kitchen S. Measuring factor IX activity of nonacog beta pegol with commercially available one-stage clotting and chromogenic assay kits: a twocenter study. J Thromb Haemost 2016;14(7):1428-1435

44 Holm PK, Sorensen MH, Hermit MB, Ezban M. The Activity of GlycoPEGylated Recombinant FIX (N9-GP) can be Measured in Two-Stage Chromogenic and One-Stage Clotting Assays,. 2013; PB 3.49-1, Abstract at XXIV Congress of the International Society on Thrombosis and Haemostasis. Available at: http://www.eventure-online.com/eventure/publicAbstractView.do?\&\#x00A0; id=217022\&congressId=6839. Accessed March 24, 2014

45 Tiefenbacher S, Amiral J, Bowyer A, et al. Qualification of selected one-stage APTT and chromogenic assays for the post-administration monitoring of nonacog beta pegol (Abstract). J Thromb Haemost 2016;14(Suppl 1):56

46 Robinson MM, Tiefenbacher S, Ross EL, et al. Comparison of FIX activity of select novel recombinant FIX replacement products in commonly used FDA approved one-stage clot assay systems. (Abstract)J Thromb Haemost 2015;13(Suppl 2):325

47 Sommer JM, Buyue Y, Bardan S, et al. Comparative field study: impact of laboratory assay variability on the assessment of recombinant factor IX Fc fusion protein (rFIXFc) activity. Thromb Haemost 2014;112(5):932-940

48 Santagostino E, Negrier C, Klamroth R, et al. Safety and pharmacokinetics of a novel recombinant fusion protein linking coagulation factor IX with albumin (rIX-FP) in hemophilia B patients. Blood 2012;120(12):2405-2411

49 St Ledger K, Fuessner A, Kalina U, Jacobs I, Voigt C, BensenKennedy D. Performance of a recombinant fusion protein linking coagulation factor IX with albumin (rFIX-FP) in the one -stage assay. Haemophilia 2016;22(Suppl 4):60(Abstract)

50 Medical and Scientific Advisory Council (MASAC) of National Hemophilia FoundationStatement regarding use of various clotting factor assays to monitor factor replacement therapy. Document \#228. Available at: http://www.hemophilia.org/sites/default/files/ document/files/masac-228.pdf. Accessed September 30, 2016

51 Kitchen S, Blakemore J, Friedman KD, et al. A computer-based model to assess costs associated with the use of factor VIII and factor IX one-stage and chromogenic activity assays. J Thromb Haemost 2016;14(4):757-764 